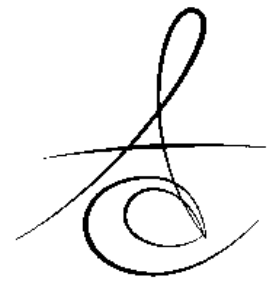

\title{
BİR DİŞ HEKİMLİĞİ FAKÜLTESİNDE KONİK IŞINLI BİLGİSAYARLI TOMOGRAFI TETKİKİ İSTENMESİNİN SEBEPLERİ
}

\section{REASONS FOR REQUESTING CONE BEAM COMPUTED TOMOGRAPHY EXAMINATION IN A FACULTY OF DENTISTRY}

\author{
Dr. Öğr. Üyesi Mehmet AMUK*
}

Arş. Gör.Serkan YILMAZ*

Makale Kodu/Article code: 3998

Makale Gönderilme tarihi: 28.02.2019

Kabul Tarihi: 10.06.2019

\section{ÖZ}

Amaç: Bu çalışmada, diş hekimliği fakültemizde Konik Işınlı Bilgisayarlı Tomografi (KIBT) görüntüleme istek sebeplerinin belirlenmesi, sınıflandırılması ve buna göre hangi sebeplerin daha yaygın olarak KIBT görüntüleme gerektirdiğinin incelenmesi amaçlanmıştır.

Gereç ve Yöntem: Erciyes Üniversitesi Diş Hekimliği Fakültesi Ağız, Diş ve Çene Radyolojisi Anabilim Dalı́na KIBT görüntülemesi için başvuran hastaların arşiv kayıtlarından alınan 21953 adet KIBT istek formu retrospektif olarak değerlendirildi. İstek yapılan maksillofasiyal bölgeler (maksilla, mandibula, maksilla-mandibula, temporomandibular eklem, paranazal sinus) kaydedildi. Bu kayıtlar istek sebepleri olan lezyon, gömülü diş, implant, travma, ortodonti ve diğer nedenler olarak 1-6 arasında kodlandı. Hastaların hangi kliniklerden yönlendirildiği, cinsiyet ve yaş dağılımlarına göre çekilen KIBT sayıları tablo haline getirildi. Veriler tanımlayıcı istatistik yöntemi ile analiz edildi.

Bulgular: Çalışmaya dahil edilen 21953 KIBT görüntüsünün \%39,39'u erkek, \%60,61'i kadın bireylere aittir. Tüm KIBT istek nedenlerinde implant değerlendirme sebebi \%33,38 ile ilk sırada yer aldı. Sadece mandibuladan yapılan isteklerde gömülü diş sebebi ilk sıradayken sadece maksillanın görüntülenme nedenlerinde ise implant değerlendirilmesinin ilk sırada olduğu görüldü. Tüm istek formları içinde lezyon değerlendirmesinin oranı \%12,92 olarak kaydedilirken, gömülü diş değerlendirmesi $\% 32,43$, paranazal sinus değerlendirmesi $\% 4,5$ ve TME değerlendirmesi ise $\% 3,82$ olarak kaydedildi.

Sonuç: Çalışmanın sonuçları KIBT görüntülenmesinin en fazla implant planlaması için istendiğini göstermektedir. Ayrıca KIBT isteklerinin bölümlere göre dağılımları hakkında bilgi vermektedir.

Anahtar Kelimeler: Konik Işınlı Bilgisayarlı Tomografi, KIBT, Radyoloji

\section{ABSTRACT}

Aim: In this study, it is aimed to determine and categorize the reasons for Cone Beam Computed Tomography (CBCT) imaging requests in our faculty of dentistry; accordingly, to analyze which reasons require $\mathrm{CBCT}$ imaging more often.

Material and Methods: 21953 CBCT request forms, obtained from the archive records of the patients who were admitted to Erciyes University Faculty of Dentistry Department of Oral and Maxillofacial Radiology for CBCT imaging, were evaluated retrospectively. Requested maxillofacial regions (maxilla, mandibula, maxilla-mandibula, temporomandibular joint, paranasal sinus) were recorded. These records were coded between 1-6 for the requests, namely lesion, impacted tooth, implant, trauma, orthodontics, and other causes. Performed CBCT images are tabulated according to the clinics requesting the imaging and the distribution of patients in terms of age and sex. The data were analyzed by descriptive statistics methods.

Results: Of the 21953 CBCT included in the study, $39.39 \%$ belongs to male and $60.61 \%$ to female individuals. Among all CBCT request reasons, the evaluation of the implant was placed first with $33.38 \%$. While among the requests made only from mandibula, the imaging of the impacted tooth was in the first place, among the requests made only from maxilla the evaluation of the implant was the most dominant reason. Among all the request forms, the ratio of lesion evaluation was recorded as $12.92 \%$, while the impacted tooth evaluation as $32.43 \%$, paranasal sinus evaluation as $4.5 \%$, and the TME as $3.82 \%$.

Conclusions: The results of the study showed that most of the CBCT images were requested for implant planning. Additionally the results provide information about the distribution of requests per clinic.

Keywords: Cone Beam Computed Tomography, $\mathrm{CBCT}$, Radiology

\footnotetext{
* Erciyes Üniversitesi Diş Hekimliği Fakültesi Ağız Diş ve Çene Radyolojisi Anabilim Dalı, Kayseri
} 


\section{GİRIŞ}

Konik Işınlı Bilgisayarlı Tomografi (KIBT) görüntüleme, panoramik radyografiden sonra maksillofasiyal görüntülemede en önemli teknolojik ilerlemedir. ${ }^{1}$ KIBT görüntüleme ilk olarak 1980'lerin başında anjiografi için geliştirilmiştir. Ayrıca KIBT geleneksel Bilgisayarlı Tomografi (BT)'ye bir alternatif olarak sunulmuş ve nispeten daha ekonomik bir radyasyon detektörü kullanmaktadır. Daha kısa bir inceleme süresi sağlayan bu sistemin belirgin avantajları arasında konik ışın kullanımından dolayı daha az radyasyon dozu ile görüntü oluşturması, hastanın translasyonundan kaynaklanan görüntü uyuşmazlığının azaltılması ve artan X-ışını tüpü verimliliği bulunmaktadır. Bununla birlikte, özellikle daha büyük görüntü alanı (FOV)'lar ile birlikte ana dezavantajı, büyük miktarda saçılmış radyasyonun tespit edilmesi nedeniyle görüntü kalitesinde gürültü ve kontrast çözünürlüğü ile ilgili bir sınırlamadır. ${ }^{2,3}$ KIBT, 1990'ı yıllardan itibaren diş hekimliği alanında kullanılmaya başlanmıştır ve maksillofasiyal yapıların üç boyutlu incelenmesine imkan sağlamıştır. ${ }^{4}$

KIBT tarayıcıların kullanımı kolaydır ve KIBT tarayıcıları diş hekimliği pratiğini uygun hale getiren panoramik radyografik makineler ile aynı alanı kaplarlar. ${ }^{3}$ Radyasyon dozu; görüş alanının boyutunu azaltmak, voksel boyutunu arttırmak ve/veya X Işını kaynağı hastanın etrafında dönerken çekilen projeksiyon görüntülerinin sayısını azaltmak suretiyle daha da azaltılabilir. ${ }^{5}$

KIBT'nin yaygın kullanımı ile oral ve maksillofasiyal radyolojinin çalışma alanı genişlemiş olup kullanımı sadece radyoloji alanında sınırlı kalmayıp diş hekimliğinin bütün bölümleri için farklı alanlarda fayda göstermiştir. Konik ışınlı görüntüleme, diş hekimliğinde yumuşak doku ayrımları gerektiren görevlerin aksine dişler ve kemik gibi yüksek kontrastlı nesneleri görüntülemede kullanılır. ${ }^{1}$ KIBT görüntülemenin faydalarının aksine radyasyon dozunun tek bir konvansiyonel periapikal radyograf veya panoramik radyograftan yüksek olduğu bilinmektedir. ${ }^{6}$ Bu bilinçle KIBT görüntüleme öncesinde her radyografik incelemede olduğu gibi gerekçelendirilmeli ve KIBT'nin potansiyel faydalarının iyonlaştırıcı radyasyona maruz kalmaya bağlı olarak getireceği zararlardan ağır basmalıdır. [International Commission on Radiological Protection (ICRP 2007)]. Bir radyolojik inceleme, radyasyon dozlarını ve radyoaktif materyallerin salınımını en aza indirmek için tasarlanmış bir güvenlik prensibi olan ALARA (As Low As Reasonably Achievable) ile yapılmalıdır.

KIBT görüntülemeye gereksinim duyulan nedenler arasında birçok sebep sayılabilir ve bu sebeplerin sınıflandırılması ile standardize edilmesi KIBT isteği yapacak hekimler için fayda sağlayacaktır. Literatürde KIBT isteğinin hangi durumlarda yapılabileceği bildirilmiştir.

\section{KIBT Görüntülemeye Başvurulan Sebepler ${ }^{1}$ :}

Cerrahi Anabilim Dalında implant planlamasında bölgenin değerlendirilmesi ve maksillofasiyal patolojiler, temporomandibular eklem (TME) değerlendirilmesi, mandibular üçüncü molar dişlerin lokalizasyonunu belirlemek amacıyla KIBT istenebilmektedir.

Endodonti Anabilim Dalında şüpheli karmaşık morfolojisi olan dişlerde olası aksesuar kanalların ve kök kanal sistem anomalilerinin tanımlanması, kök kurvatürünün belirlenmesi, çelişkili, özgün olmayan klinik bulgu ve belirtileri ya da konvansiyonel radyografik bulguları olan hastalarda dental periapikal patoloji tanısı, eksternal kök rezorpsiyonunun internal kök rezorpsiyonu ya da invaziv servikal rezorpsiyondan ayırt edilmesi ve lokalizasyonunu değerlendirmede KIBT kullanılır.

Ağız Diş ve Çene Radyolojisi Anabilim Dalında ise maksillofasiyal patolojilerin, TME değerlendirilmesi, gömülü diş lokalizasyonunun ve anatomik yapılar ile yakınlığının belirlenmesi amacıyla KIBT isteği yapılmaktadır. ${ }^{1}$

Ortodonti Anabilim Dalında ise KIBT modellerinde hava yolundaki anomaliler ve/veya daralma alanları, gömülü dişlerin pozisyonları ve sürdürülebilirlikleri üç boyutlu olarak belirlenebilir ve hacim ölçümü yapılabilir. Bu görüntüleme tekniği ile tüm hava yolu izlenebilir. ${ }^{7}$

Çalışmamızda, diş hekimliği fakültemizde KIBT istek sebeplerini, KIBT görüntülerinin hangi anabilim dallarından istendiğini, cinsiyet ayrımını ve bu sonuçlara göre hangi sebeplerin daha yaygın olarak KIBT görüntüleme gerektirdiği amaçlanmıştır.

\section{GEREÇ VE YÖNTEMLER}

Bu araştırma, Erciyes Üniversitesi Klinik Araştırmaları Etik Kurulu'nun vermiş olduğu 2019/31 karar numaralı etik kurul karar formu ile onaylanmıştır.

Erciyes Üniversitesi Diş Hekimliği Fakültesi Ağız, Diş ve Çene Radyolojisi Anabilim Dalı́na, Ocak 2012 ile 
Haziran 2018 tarihleri arasında, KIBT görüntülemesi için başvuran hastalardan alınan 21953 adet KIBT istek formları anabilim dalı arşiv kayıtlarından alınarak retrospektif olarak değerlendirildi. Bu istekler fakültedeki klinikler, özel muayenehaneler ve çeşitli hastaneler ve ağız diş sağlığı merkezlerinden yapılmıştır. Fakülte dışı yapılan istekler fakültenin KIBT istek formu doldurularak kabul edilmektedir.

İstek yapılan maksillofasiyal bölgeler (maksillamandibula-tme-paranazal sinus) kaydedildi, hastaların hangi kliniklerden yönlendirildiği, cinsiyet ve yaş dağıIımlarına göre çekilen KIBT sayıları tablo haline getirildi. Veriler tanımlayıcı istatistik yöntemi ile analiz edildi.

İncelenen 21953 adet KIBT istem formu öncelikle istek yapılan maksillofasiyal bölgelere göre tablo haline getirildi. (Tablo 1) Bu tabloya göre üst çene, alt-üst çene, alt çene, temporomandibular eklem (TME) ve paranasal sinus (PS) olarak ayrıldı. Bu sınıflama kendi arasında ise nedenlere göre kodlandı. Lezyon, gömülü diş, implant, travma, ortodonti ve diğer nedenler olarak 1-6 arası numaralandı. Diğer nedenler ayrıntılı olarak sınıflandırıldı. Diğer başlığı altında yer alan ve açıklaması yer almayan tomografi istekleri, fakültemize tıp fakültesi hastanesinden yönlendirilen, diş hekimliği fakültesi bünyesinde teşhis ve tedavi planlaması kapsamında yer almayan hastalar olup, bu isteklerin sayısı \%1'in altında kaldığı için açıklamalarının yapılması gerekli görülmemiştir. (Tablo 1) TME ve PS isteklerinde kodlama kullanılmadı.

Tablo 1. KIBT istek formunda bulunan maksillofasiyal bölgeler ve istek sebepleri.

\begin{tabular}{|c|c|c|c|c|c|}
\hline \multicolumn{6}{|c|}{ MAKSİLLA } \\
\hline Max-1 & Max-2 & Max-3 & Max-4 & Max-5 & Max-6 \\
\hline Lezyon & Gömülü Diş & İmplant & Kirık & Ortodonti & Diğer \\
\hline \multicolumn{6}{|c|}{ MANDİBULA } \\
\hline Mand-1 & Mand-2 & Mand-3 & Mand-4 & Mand-5 & Mand-6 \\
\hline Lezyon & Gömülü Diş & İmplant & Kırık & Ortodonti & Diğer \\
\hline \multicolumn{6}{|c|}{ MAKSÍLLA VE MANDİBULA } \\
\hline $\begin{array}{l}\text { Max- } \\
\text { Mand-1 }\end{array}$ & $\begin{array}{c}\text { Max- } \\
\text { Mand-2 }\end{array}$ & $\begin{array}{c}\text { Max- } \\
\text { Mand-3 }\end{array}$ & $\begin{array}{c}\text { Max- } \\
\text { Mand-4 }\end{array}$ & Max-Mand-5 & $\begin{array}{c}\text { Max- } \\
\text { Mand-6 }\end{array}$ \\
\hline Lezyon & Gömülü Diş & İmplant & Kırık & Ortodonti & Diğer \\
\hline \multicolumn{6}{|c|}{ TEMPORAMANDİBULAR EKLEM } \\
\hline \multicolumn{6}{|c|}{ TME } \\
\hline \multicolumn{6}{|c|}{ PARANASAL SİNÜSLER } \\
\hline \multicolumn{6}{|c|}{ SiN-6 } \\
\hline
\end{tabular}

Max-1: Sadece üst çeneden istenen lezyon sebepli istekler, Max-2: Sadece üst çeneden istenen gömülü dis sebepli istekler, Max-3: Sadece üst çeneden istenen implant sebepli istekler, Max-4: Sadece üst çeneden istenen fraktür sebepli istekler, Max-5: Sadece üst çeneden istenen ortodontik sebepli istekler, Max-6: Sadece üst ceneden istenen diğer istekler, Mand-1: Sadece alt çeneden istenen lezyon sebepli istekler, Mand-2: Sadece alt çeneden istenen gömülü diş sebepli istekler, Mand-3: Sadece alt çeneden istenen implant sebepli istekler, Mand-4: Sadece alt çeneden istenen fraktür sebepli istekler, Mand-5: Sadece alt çeneden istenen ortodontik sebepli istekler, Mand-6: Sadece alt çeneden istenen diğer istekler, MaxMand-1: Her iki çeneden istenen lezyon sebepli istekler, Max-Mand-2:
Her iki çeneden istenen gömülü diş sebepli istekler, Max-Mand-3: Her iki çeneden istenen implant sebepli istekler, Max-Mand-4: Her iki çeneden istenen fraktür sebepli istekler, Max-Mand-5: Her iki çeneden istenen ortodontik sebepli istekler, Max-Mand-6: Her iki çeneden istenen diğer istekler, TME: Temporamandibular eklemin görüntülenmesi sebepli istekler, SIN-6: Paranasal sinüslerin görüntülenmesi sebepli istekler.

Tablo 2. Diğer başlığı altında istek yapılan KIBT sayı ve ayrıntılı açıklamaları

\begin{tabular}{|l|c|c|}
\cline { 2 - 3 } \multicolumn{1}{c|}{} & $\begin{array}{l}\text { İstek } \\
\text { Sayısı }\end{array}$ & $\begin{array}{l}\text { Yüzdesi } \\
\text { (\%) }\end{array}$ \\
\hline $\begin{array}{l}\text { Pre-operatif Ortognatik Cerrahi hastası } \\
\text { değerlendirilmesi }\end{array}$ & 314 & 15.66 \\
\hline $\begin{array}{l}\text { Post-operatif Ortognatik Cerrahi hastası } \\
\text { değerlendirilmesi }\end{array}$ & 346 & 17.25 \\
\hline $\begin{array}{l}\text { Anatomorfolojik değişiklikler ve Maksillofasiyal } \\
\text { Sendromların değerlendirilmesi }\end{array}$ & 442 & 22.4 \\
\hline Dudak Damak Yarıklı hastaların değerlendirilmesi & 146 & 7.28 \\
\hline Diş Anomalilerinin değerlendirilmesi & 277 & 13.81 \\
\hline $\begin{array}{l}\text { Major cerrahi girişimlerin (Ortognatik Cerrahi hariç) } \\
\text { Post-operatif ve takip değerlendirilmesi }\end{array}$ & 407 & 20.29 \\
\hline İdiopatik ağıı değerlendirilmesi & 33 & 1.64 \\
\hline Temporal kemik değerlendirilmesi & 23 & 1.14 \\
\hline Hariç bırakılanlar* & 17 & 0.84 \\
\hline Toplam & $\mathbf{2 0 0 5}$ & $\mathbf{1 0 0}$ \\
\hline *Tomografi isteklerinin sayıSı \%1'in altında kaldığı için açıklamalarının \\
yapıIması gerekli görülmemiştir
\end{tabular}

\section{BULGULAR}

Çalışmaya dahil edilen 21953 KIBT'den $\% 39,07$ 'u erkek, \%60,93'ü kadın bireydi. Elde edilen verilere göre üst çeneden 5580 adet, alt çeneden 9446 adet ve alt-üst çenelerin birlikte olduğu 5097 adet tomografi isteği yapılmıştı. 839 adet TME 991 adet ise PS patolojisi değerlendirmek amaçlı KIBT isteği yapıldığı görüldü. İstek yapılan hastaların yaş ve cinsiyetlerine göre sınıflandırıması yapıldı (Tablo 3). Bu verilere göre ise 2440 erkek hastadan maksilla kaynaklı, 3442 erkek hastadan mandibular kaynaklı KIBT istemi yapıldığı kaydedildi. Tüm erkek hastaların yaş ortalaması 32,65 olarak bulundu. Kadın hastaların ise 3140'inden maksilla sebepli, 6004'inden mandibula sebepli KIBT istemi yapıldığı görüldü. Tüm kadın hastaların yaş ortalaması ise 33,77 olarak bulundu.

Maksilla ve mandibulada KIBT isteklerinin nedenlerinin yüzdelik dağıımı ve istek sayıları kaydedildi. (Tablo 4) Tüm KIBT istek nedenleri ele alındığında implant değerlendirme sebebi \%33,38 ile ilk sırada yer aldı. Sadece mandibulanın görüntülenmesini isteyen formlarda da gömülü diş sebebi ilk sıradaydı. Sadece maksillanın görüntülenme nedenlerinde ise implant değerlendirilmesinin ilk sırada olduğu görüldü. Lezyon değerlendirme sebebi ile yapılan istekler tüm isteklerin \%12,92'sini oluşturmaktaydı. Gömülü diş değerlendirmesi için yapılan isteklerin ise tüm isteklere oranı $\% 32,33$ olarak bulundu. Ortodontik sebepli istekler

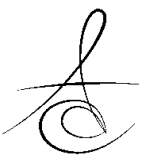


göz önüne alındığında sadece mandibuladan ortodontik sebepli istek olmadığı görüldü. PS değerlendirme \%4,5 ve TME değerlendirmesi ise \%3,82 olarak kaydedildi. (Tablo 5) Maxilla, mandibula ve her iki çenenin de istendiği KIBT'lerde cinsiyet olarak kadınlardan daha çok istek yapıldığı görüldü.

KIBT isteği yapan klinik bölümlere göre dağılıma bakıldığında ise en çok isteğin Ağız, Diş ve Çene Cerrahisi Anabilim Dalından yapıldığı görüldü. (Tablo 6) Bu kliniği ikinci sırada Ağız, Diş ve Çene Radyolojisi Anabilim Dalının izlediği saptandı. En az isteğin ise Restoratif Diş Tedavisi Anabilim Dalından yapıldığı belirlendi.

Tablo 3. KIBT istek formunda bulunan maksillofasiyal bölgeler ve istek sebeplerinin sayısı ve cinsiyetlere göre dağılımı.

\begin{tabular}{|c|c|c|c|c|c|c|}
\hline & \begin{tabular}{|c|} 
ÍSTENEN \\
KIBT \\
SAYISI \\
\end{tabular} & $\begin{array}{l}\text { ERKEK } \\
\text { SAYISI }\end{array}$ & $\begin{array}{l}\text { KADIN } \\
\text { SAYISI }\end{array}$ & \begin{tabular}{|c|} 
ERKEK \\
YAŞ ORT.
\end{tabular} & \begin{tabular}{|c|} 
KADIN \\
YAŞ ORT.
\end{tabular} \\
\hline Max-1 & Lezyon & 1090 & 517 & 573 & 30,05 & 37,31 \\
\hline Max-2 & Gömülü diş & 1479 & 604 & 875 & 24,04 & 28,52 \\
\hline Max-3 & İmplant & 1928 & 782 & 1146 & 46,09 & 44,04 \\
\hline Max-4 & Kirik & 19 & 12 & 7 & 28,24 & 32,31 \\
\hline Max-5 & Ortodonti & 59 & 29 & 30 & 17,13 & 20,35 \\
\hline Max-6 & Diğer & 1005 & 496 & 509 & 31,33 & 33,26 \\
\hline \multicolumn{2}{|c|}{ Maksilla- Toplam } & 5580 & 2440 & 3140 & 29,48 & 32,63 \\
\hline Mand-1 & Lezyon & 1607 & 935 & 672 & 36,14 & 35,78 \\
\hline Mand-2 & Gömülü diş & 5290 & 1679 & 3611 & 28,64 & 26,55 \\
\hline Mand-3 & İmplant & 2045 & 638 & 1407 & 50,31 & 48,08 \\
\hline Mand-4 & Kirık & 75 & 40 & 35 & 32,61 & 33,58 \\
\hline Mand-5 & Ortodonti & - & - & - & - & - \\
\hline Mand-6 & Diğer & 429 & 150 & 279 & 35,66 & 37,83 \\
\hline \multicolumn{2}{|c|}{ Mandibula- Toplam } & 9446 & 3442 & 6004 & 36,67 & 36,36 \\
\hline Max-Mand-1 & Lezyon & 140 & 60 & 80 & 33,34 & 30,63 \\
\hline Max-Mand-2 & Gömülü diş & 329 & 87 & 242 & 24,34 & 27,45 \\
\hline Max-Mand-3 & İmplant & 3356 & 1199 & 2157 & 47,32 & 45,32 \\
\hline Max-Mand-4 & Kirik & 50 & 2 & 48 & 27,62 & 24,41 \\
\hline Max-Mand-5 & Ortodonti & 651 & 418 & 233 & 12,89 & 13,83 \\
\hline Max-Mand-6 & Diğer & 571 & 247 & 324 & 41,00 & 47,89 \\
\hline \multicolumn{2}{|c|}{ Maksilla-Mandibula Toplam } & 5097 & 2013 & 3084 & 30,91 & 31,58 \\
\hline TME & $\begin{array}{l}\text { Temporam } \\
\text { andibular } \\
\text { Eklem }\end{array}$ & 839 & 285 & 554 & 37,76 & 38,65 \\
\hline SİN-6 & $\begin{array}{l}\text { Paranasal } \\
\text { Sinüsler }\end{array}$ & 991 & 399 & 592 & 28,47 & 29,63 \\
\hline \multicolumn{2}{|c|}{ Genel Toplam } & 21953 & $\begin{array}{c}8579 \\
(\% 39,07)\end{array}$ & $\begin{array}{c}13374 \\
(\% 60,93)\end{array}$ & & \\
\hline
\end{tabular}

Max-1: Sadece üst çeneden istenen lezyon sebepli istekler, Max-2: Sadece üst çeneden istenen gömülü diş sebepli istekler, Max-3: Sadece üst çeneden istenen implant sebepli istekler, Max-4: Sadece üst ceneden istenen fraktür sebepli istekler, Max-5: Sadece üst çeneden istenen ortodontik sebepli istekler, Max-6: Sadece üst çeneden istenen diğer istekler, Mand-1: Sadece alt çeneden istenen lezyon sebepli istekler, Mand-2: Sadece alt ceneden istenen gömülü dis sebepli istekler, Mand-3: Sadece alt çeneden istenen implant sebepli istekler, Mand-4: Sadece alt çeneden istenen fraktür sebepli istekler, Mand-5: Sadece alt çeneden istenen ortodontik sebepli istekler, Mand6: Sadece alt çeneden istenen diğer istekler, Max-Mand-1: Her ik çeneden istenen lezyon sebepli istekler, Max-Mand-2: Her iki çeneden istenen gömülü diş sebepli istekler, Max-Mand-3: Her iki çeneden istenen implant sebepli istekler, Max-Mand-4: Her iki çeneden istenen fraktür sebepli istekler, Max-Mand-5: Her iki çeneden istenen ortodontik sebepli istekler, Max-Mand-6: Her iki çeneden istenen diğer istekler, TME: Temporamandibular eklemin görüntülenmesi sebepli istekler, SIN-6: Paranasal sinüslerin görüntülenmesi sebepli istekler.

Tablo 4. KIBT istek formunda bulunan maksillofasiyal bölgeler ve istek sebeplerinin sayısı ve yüzdesi.

\begin{tabular}{|c|c|c|c|}
\hline & \multirow{2}{*}{$\begin{array}{l}\begin{array}{l}\text { ISTENEN } \\
\text { KIBT SAYISI }\end{array} \\
1090\end{array}$} & \multirow{2}{*}{\begin{tabular}{l} 
KIBT \\
YÜZDELER \\
I (\%) \\
\multicolumn{1}{|c}{4.96}
\end{tabular}} \\
\hline Max-1 & Lezyon & & \\
\hline Max-2 & Gömülü diş & 1479 & 6.73 \\
\hline Max-3 & İmplant & 1928 & 8.78 \\
\hline Max-4 & Kırık & 19 & 0.08 \\
\hline Max-5 & Ortodonti & 59 & 0.26 \\
\hline Max-6 & Diğer & 1005 & 4.57 \\
\hline \multicolumn{2}{|c|}{ Maksilla - Toplam } & 5580 & 25,38 \\
\hline Mand-1 & Lezyon & 1607 & 7.32 \\
\hline Mand-2 & Gömülü diş & 5290 & 24.09 \\
\hline Mand-3 & İmplant & 2045 & 9.31 \\
\hline Mand-4 & Kırık & 75 & 0.34 \\
\hline Mand-5 & Ortodontik & - & - \\
\hline Mand-6 & Diğer & 429 & 1.95 \\
\hline \multicolumn{2}{|c|}{ Mandibula - Toplam } & 9446 & 43,01 \\
\hline Max-Mand-1 & Lezyon & 140 & 0.63 \\
\hline Max-Mand-2 & Gömülü diş & 329 & 1.49 \\
\hline Max-Mand-3 & İmplant & 3356 & 15.28 \\
\hline Max-Mand-4 & Kırık & 50 & 0.22 \\
\hline Max-Mand-5 & Ortodontik & 651 & 2.96 \\
\hline Max-Mand-6 & Diğer & 571 & 2.60 \\
\hline \multicolumn{2}{|c|}{ Maksilla- Mandibula Toplam } & 5097 & 23,18 \\
\hline TME & Temporamandibular Eklem & 839 & 3.82 \\
\hline SİN-6 & Paranasal Sinüsler & 991 & 4.51 \\
\hline \multicolumn{2}{|c|}{ Genel Toplam } & 21953 & 100 \\
\hline
\end{tabular}

Max-1: Sadece üst çeneden istenen lezyon sebepli istekler, Max-2: Sadece üst çeneden istenen gömülü diş sebepli istekler, Max-3: Sadece üst çeneden istenen implant sebepli istekler, Max-4: Sadece üst çeneden istenen fraktür sebepli istekler, Max-5: Sadece üst çeneden istenen ortodontik sebepli istekler, Max-6: Sadece üst çeneden istenen diğer istekler, Mand-1: Sadece alt çeneden istenen lezyon sebepli istekler, Mand-2: Sadece alt çeneden istenen gömülü diş sebepli istekler, Mand-3: Sadece alt çeneden istenen implant sebepli istekler, Mand-4: Sadece alt çeneden istenen fraktür sebepli istekler, Mand-5: Sadece alt çeneden istenen ortodontik sebepli istekler, Mand-6: Sadece alt çeneden istenen diğer istekler, Max-Mand-1: Her iki çeneden istenen lezyon sebepli istekler, Max-Mand-2: Her iki çeneden istenen gömülü diş sebepli istekler, Max-Mand-3: Her iki çeneden istenen implant sebepli istekler, Max-Mand-4: Her iki çeneden istenen fraktür sebepli istekler, Max-Mand-5: Her iki çeneden istenen ortodontik sebepli istekler, Max-Mand-6: Her iki çeneden istenen diğer istekler, TME: Temporamandibular eklemin görüntülenmesi sebepli istekler, SIN-6: Paranasal sinüslerin görüntülenmesi sebepli istekler.

Tablo 5. KIBT istek formunda bulunan nedenler ve istek sebeplerinin yüzdesi.

\begin{tabular}{|l|c|c|}
\hline KIBT İSTEK NEDENLERI & KIBT SAYISI & YÜZDE (\%) \\
\hline Lezyon & 2837 & 12.92 \\
\hline Gömülü Diş & 7098 & 32.33 \\
\hline İmplant & 7329 & 33.38 \\
\hline Kırık & 144 & 0.65 \\
\hline Ortodonti & 710 & 3.23 \\
\hline Diğer & 2005 & 9.13 \\
\hline TME & 839 & 3.82 \\
\hline Paranasal Sinüs & 991 & 4.51 \\
\hline Toplam & $\mathbf{2 1 9 5 3}$ & $\mathbf{1 0 0}$ \\
\hline TME: Temporamandibular eklemin görüntülenmesi sebepli istekler.
\end{tabular}

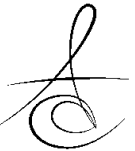


Tablo 6. KIBT isteklerinin yapıldığı anabilim dalları ve sayıları.

\begin{tabular}{|l|c|c|}
\hline Anabilim Dalı & $\begin{array}{l}\text { KIBT İstek } \\
\text { Sayısı }\end{array}$ & $\begin{array}{l}\text { Yüzde } \\
(\%)\end{array}$ \\
\hline Ağız, Diş ve Çene Cerrahisi A.D. & 9345 & 42.56 \\
\hline Ağız, Diş ve Çene Radyolojisi A.D. & 6618 & 30.14 \\
\hline Periodontoloji A.D. & 4343 & 19.78 \\
\hline Ortodonti A.D. & 616 & 2.80 \\
\hline Protetik Diş Tedavisi A.D & 486 & 2.21 \\
\hline Endodonti A.D. & 347 & 1.58 \\
\hline Çocuk Diş Hekimliği A.D. & 140 & 0.63 \\
\hline Restoratif Diş Tedavisi A.D. & 58 & 0.26 \\
\hline Toplam & $\mathbf{2 1 9 5 3}$ & $\mathbf{1 0 0}$ \\
\hline
\end{tabular}

\section{TARTIŞMA}

Çalışmamızda diş hekimliği fakültesine KIBT görüntüleme için başvuran hastaların istek formları değerlendirilmiştir. Bu istek formlarında belirli bir sınıflandırma yapılmıştır. Böylece hangi sebeplerle KIBT isteği yapıldığı araştııııııșır. KIBT istemi yapan kliniklerin ve sebeplerin sayısal olarak analizleri yapılıp değerlendirilmiştir.

Literatürde bu alanda yapılan çalışmaların verileri ile karşılaştırıldığında Akarslan ve ark. ${ }^{8}$ yaptığı çalışmada 1087 adet istek formu değerlendirilmiş ve tetkiklerin en fazla implant değerlendirmesi için yapııdığı ve gömülü dişler için ise en fazla maksilladan istek yapıldığı ortaya koyulmuştur. Ertaş ve ark. ${ }^{9}$ yaptıkları çalışmada ise 470 adet istek formu içinde en fazla isteğin gömülü diş sebebi ile yapıldığını bunu tümor ve kist gibi patolojik lezyonlar ile implant değerlendirmesinin izlediğini bildirmişlerdir. Bizim çalışmamızdaki verilere göre de implant değerlendirme sebebi ile yapılan istekler en fazla çıkarken bunu ikinci sırada gömülü diş değerlendirmesi için yapılan istekler izlemiştir. Gömülü dişler için en fazla mandibuladan istek yapııldığı belirtilmiştir. Literatürde bu durumla ilgili olarak KIBT görüntüleri mandibular 3. molar dişlerin mandibular kanal ile olan ilişkisinin değerlendirilmesinde rutin olarak değil, sadece konvansiyonel tekniklerde diş köklerinin mandibular kanal kortikal sınırında kesiti izlendiğinde ve ilgili diş köklerinin mandibular kanal üzerine süperpoze olduğu durumlarda gerekli olduğu belirtilmektedir. ${ }^{10}$ Ayrıca çalışmada sadece mandibuladan ortodontik sebeple KIBT istenmediği görülmüştür. Bunun sebebi ortodonti hastalarında alt ve üst çenenin kafa kaidesine göre pozisyonunun değerlendirilmesi amacıyla maksilla ve mandibuladan birlikte KIBT isteği yapılmakla beraber sadece maksilladan yapılan ortodontik istek sebeplerinin nasal kavite ve/veya maksiller sinus ile ilişkisi olduğu düşünülen kanin dişlerin pozisyonunu değerlendirmek için istendiği saptanmıştır.

İmplant için yapılan istekler en fazla sayıda çıkmıştır. Amerikan Oral ve Maksillofasiyal Radyoloji Akademisi (AOMR), implant değerlendirilmesi için KIBT istemi yapılmasını destekleyici bir makalesini 2012 yllında yayınlamış ve KIBT görüntüleme yöntemini uygun bulmuştur. ${ }^{11}$ Ancak implant değerlendirilmesi için KIBT isteği yapılırken yine maruz kalınan radyasyon dozu ve hastaya bu tetkikin sağlayacağı fayda değerlendirilmelidir. Bu sebeple radyasyonun zararlı etkilerinden korunulması amacıyla birden fazla implant yerleştirilecek vakalarda KIBT istemi yapılması önerilmektedir. ${ }^{12}$

Çalışmamızda elde edilen bir diğer sonuç ise kliniklerin KIBT isteme sayıları olmuştur. Bu sayılar değerlendirildiğinde çocuk diş hekimliği kliniğinin endodonti kliniğinden fazla sayıda KIBT istediği görülmüştür. Literatürde çocuk diş hekimliğinde KIBT kullanımına yönelik endikasyonlar henüz yeterince ele alınmamıştır. KIBT görüntüleme çocuk diş hekimliğinde elbette uygulanmaktadır ancak hastaya bireysel olarak gerekçelendirilmeli ve fayda hesabı doğru yapılmaIıdır. ${ }^{13}$ Endodonti alanınında ise yapılan çalışmalarda daha yaygın kullanılmakta olduğu görülmüştür. Rodriquez ve ark. ${ }^{14}$ yaptıkları çalışmada KIBT görüntülerinin tedavi yapan uzman hekimlerin tedavi seçeneklerini değiştirip değiştirmeyeceğini araştırmışlar ve KIBT görüntülemenin klinisyenlerin endodontik vakalarda karar verme davranışlarını değiştirme potansiyeli olan yararlı bir araç olduğunu göstermişlerdir. Araştırmacılar, vakaların \%27,3'ünde KIBT tarama sını inceledikten sonra tedavi planlarını değiştirmiştir. Bu bilgilere göre KIBT görüntülemenin hekimlerin tedavi planlarında etkili bir görüntüle yöntemi olduğu ortaya çıkmışıı.

De Vos ve ark. ${ }^{15}$ farklı diş hekimliği alanlarındaki KIBT kullanımı ile ilgili bir makale listesi hazırlamıştır. KIBT kullanımının çoğunluğu maksillofasiyal cerrahide (\%41) gözlendiğini, bunu dento-alveoler sorunların (\%29), ortodontinin (\%16) ve dental implantoloji (\%11) izlediğini bildirmişlerdir. Endodonti, periodontoloji, genel diş hekimliği ve adli diş hekimliği geri kalan \%9'luk bir oranla oluşturulmuşken, sadece \%1'i KIBT'nin kulak burun ve boğaz hastalıklarında kullanımı ile ilgili olduğunu bildimişlerdir. 
Horner ve ark. yaptıkları derleme ile KIBT görüntülemenin klinik kullanımı için bir rehber hazırlamışlardır. Bu rehber KIBT istem nedenleri ile ilgili yapılan çalışmaları ve dünya genelinde kabul görmüş kurum ve/veya kuruluşların KIBT görüntüleme kullanım odaklarını referans alınarak belirlenmiştir. Buna göre Amerikan Endodontistler Derneği 2013 yılında yayınladığı çalışmaya göre diş travmasında, Harris ve arkadaşları 2012 yııında yaptıkları çalışmada implant değerlendirmesi için, Amerikan Oral ve Maksillofasiyal Radyoloji Akademisi 2013 yllındaki çalışmasında ortodontik sebeplerle, Walter ve arkadaşları 2012 yılındaki çalışmalarında periodontoloji ve Avrupa Endodontoloji Derneği ise 2014 çalışmasında endodontik sebeplerle KIBT alınmasının uygunluğunu belirtmişlerdir. ${ }^{16}$ Bizim çalışmamızdaki sınılandırmaya uyumlu çalışmalar olarak bildirilmiştir.

Amerikan Diş Hekimliği Birliği yayınladığı çalışmada klinisyen, konvansiyonel diş röntgenlerini ve KIBT taramalarını sadece tanı veriminin hasta tedavisine fayda sağlayacağını, klinik sonuçları veya bunların tümünü önemli ölçüde iyileştireceğini beklediğinde istem yapmalıdır olarak bildirmiştir. ${ }^{17} \mathrm{Bu}$ konuda klinisyenlerin KIBT isteği yapma konusunda bilgi seviyelerinin artılırması gerektiğini düşünmekteyiz. Kamburoglu ve ark. ${ }^{18}$ yaptıkları çalışmada diş hekimliği öğrencilerine verilen KIBT eğitiminin daha ileri seviyeye taşınması gerektiğini bildirmişlerdir. Yapılan anket çalışmasında öğrencilerin KIBT konusunda bilgilerinin yetersiz olduklarına ve ayrıntılı olarak eğitim müfredatında bu konunun geliştirilmesi gerektiğini anlatmışlardır.

Dölekoğlu ve ark.19 yaptıkları anket çalışma- sında ise klinisyenlerin görüntüleme sistemleri hakkın- daki bilgilerini güncellemek ve yeni teknolojiler hakkında bilgilendirmek için radyoloji ile ilgili yüksek lisans eğitim kursları, toplantılar ve seminerler yapıl- ması gerektiği sonucuna varmışlardır. Yine bu çalış- mada klinisyenlerin en çok KIBT istek nedeni olarak implant değerlendirmesini gerekçe gösterdikleri bunu ikinci sırada şüpheli patolojik lezyonların izlediğini belirtmişlerdir. Burada özel muayenehanede çalışan klinisyenlerin gömülü diş için KIBT istemini fazla sayıda yapmamalarının sebebini bu dişlerin üniversite hastanelerinde ağız diş ve çene cerrahisi kliniklerine yönlendirilmelerinden kaynaklı olduğunu düşünmekteyiz.

Sonuç olarak yaptığımı çalışma ile KIBT in diş hekimliğinde kullanım sıklığını ve hangi kliniklerin hangi sebeplerle KIBT görüntülemeye başvurduklarını bildirdik. Bunun yanı sıra istek yapılmasının gerekip gerekmediğini bu konuda literatürdeki çalışmalarla ne ölçüde uyum gösterdiğimizi karşılaştırıp fakültemize kliniklerden gelen isteklerin dünyadaki radyoloji derneklerinin rehberlerinde belirtilen endikasyonlar ile uyum gösterdiğini düşünmekteyiz. Aynı zamanda KIBT görüntüleme endikasyonları konusunda klinisyenlerin güncel bilgilere sahip olmaları gerektiği kanısındayız.

Mehmet Amuk: ORCID ID: 0000-0001-6390-7169 Serkan Yilmaz: ORCID ID: 0000-0001-7149-0324

\section{KAYNAKLAR}

1. White SC. Cone-beam imaging in dentistry. Health Phys 2008;95:628-37.

2. MacDonald D. Cone-beam computed tomography and the dentist. J Investig Clin Dent 2017; 8: e12178.

3. Scarfe WC, Farman AG. What is cone-beam CT and how does it work? Dent Clin North Am 2008; 52: 707-30.

4. Mozzo P, Procacci C, Tacconi A, Martini PT, Andreis IB. A new volumetric CT machine for dental imaging based on the cone-beam technique: preliminary results. Eur Radiol 1998;8:1558-64.

5. Patel S, Dawood A, Ford TP, Whaites E. The potential applications of cone beam computed tomography in the management of endodontic problems. Int Endod J 2007;40:818-30.

6. Whaites E. Dose units and dosimetry. Essentials of dental radiography and radiology 4th ed London: Churchill Livingstone Elsevier 2007:25-8.

7. Kütük N, Alkan A, Amuk NG, Çoban G. Uyku Apnesinin Tedavisinde Ortognatik Cerrahinin Yeri. Turkiye Klinikleri J Oral Maxillofac Surg-Special Topics 2017;3:146-52.

8. Akarslan Z, Peker İ. Bir diş hekimliği fakültesindeki konik ışınlı bilgisayarlı tomografi incelemesi istenme nedenleri. Acta Odontol Turc 2015;32:1-6.

9. Ertaş ET, Kalabalık F. The indications for dental volumetric tomography in a turkish population sample. Atatürk Üniv Diş Hek Fak Derg 2014; 24: 232-40.

10. Neves FS, Souza T, Almeida S, Haiter-Neto F, Freitas D, Bóscolo FN. Correlation of panoramic radiography and cone beam $\mathrm{CT}$ findings in the assessment of the relationship between impacted

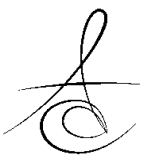


mandibular third molars and the mandibular canal. Dentomaxillofac Radiol 2012; 41:553-7.

11. Tyndall DA, Price JB, Tetradis S, Ganz SD, Hildebolt C, Scarfe WC. Position statement of the American Academy of Oral and Maxillofacial Radiology on selection criteria for the use of radiology in dental implantology with emphasis on cone beam computed tomography. Oral Surg Oral Med Oral Pathol Oral Radiol 2012;113:817-26.

12. Hatcher DC, Dial C, Mayorga C. Cone beam CT for pre-surgical assessment of implant sites. J Calif Dent Assoc 2003;31:825-34.

13. Aps J. Cone beam computed tomography in paediatric dentistry: overview of recent literature. Eur Arch Paediatr Dent 2013;14:131-40.

14. Rodríguez G, Abella F, Durán-Sindreu F, Patel $S$, Roig $M$. Influence of cone-beam computed tomography in clinical decision making among specialists. Eur Endod J 2017;43:194-9.

15. De Vos W, Casselman J, Swennen G. Cone-beam computerized tomography (CBCT) imaging of the oral and maxillofacial region: a systematic review of the literature. Int $\mathrm{J}$ Oral Maxillofac Surg 2009;38:609-25.

16. Horner K, O'Malley L, Taylor K, Glenny A. Guidelines for clinical use of CBCT: a review. Dentomaxillofac Radiol. 2014; 44:20140225.

17. Affairs ADACOS. The use of cone-beam computed tomography in dentistry: an advisory statement from the American Dental Association Council on Scientific Affairs. J Am Dent Assoc 2012;143:899902.

18. Kamburoğlu K, Kurşun Ş, Akarslan Z. Dental students' knowledge and attitudes towards cone beam computed tomography in Turkey. Dentomaxillofac Radiol. 2011;40:439-43.

19. Dölekoğlu S, Fişekçioğlu E, İlgüy M, İlgüy D. The usage of digital radiography and cone beam computed tomography among Turkish dentists. Dentomaxillofac Radiol 2011;40:379-84.

\section{Yazışma Adresi}

Mehmet AMUK

Köşk Mh. Ahmet El Biruni Cd.

Erciyes Üniversitesi Diş Hekimliği

Ağız Diş ve Çene Radyolojisi Anabilim Dalı

A Blok Melikgazi/ Kayseri Pk:38030

TIf: 03522076600 (29233)

GSM 05056524513

E-mail: mehmetamuk@gmail.com 